\title{
7. Gender-Based Evaluation of Development Projects: The LAST Method
}

\author{
Kuntala Lahiri-Dutt
}

\section{Introduction: An Alternative Inquiry}

This chapter addresses three key research questions often posed in fieldbased and participatory development research: how to effectively integrate Monitoring and Evaluation (M\&E) into the project cycle; how to integrate a gendered approach to participatory surveys; and how to use an assets-based approach as opposed to a conventional needs-based assessment. The innovation in this chapter lies in the use of a recently developed asset-based participatory M\&E method (Livelihood Asset Status Tracking or LAST), in combination with gender analysis, undertaken by participants to examine the impacts of community development projects on women and men in a coal mining region of East Kalimantan, Indonesia. The work was undertaken in and around the areas of operation of PT Kaltim Prima Coal (KPC) in Sangatta, East Kalimantan, as part of an Australian Research Council-funded Linkage Project. The Australian National University (ANU) and PT Kaltim Prima Coal are joint project partners.

\section{Two Stories}

I will start with two stories that comprise the background for this research. In early 2008, I met a senior Community Relations manager of a large multinational mining company. She had joined this company after serving a number of years with non-government development organisations, and expressed her surprise at how the mining industry has generally neglected simple M\&E processes in its community development projects. Such processes are routinely used by development and donor agencies. Indeed, the Community Development Toolkit published by the International Council on Mining and Metals (ICMM) has just one section on M\&E, but uses a Logical Framework (logframe) approach, which is based on managerial principles rather than community participation. For example, it uses a matrix of goals, outcomes, outputs and inputs against indicators and their measurement. Our idea was to explore ways in which we could go about the M\&E process that would not be essentially top-down, but 
involve community members so that the process of evaluation itself becomes an awareness raising exercise for both company personnel involved in the daily running of the projects and the community.

The other story is also personal and dates back to 2004, when the then Managing Director of KPC invited me to find out 'what the women in the community want'. It is not unusual for researchers to undertake 'needs assessments', ${ }^{1}$ and indeed such assessments of women's and men's needs and interests comprise a most important part of gender analysis for many development interventions. Consequently, I undertook a systematic needs assessment exercise with women in three village clusters around the area of mine operations (see Lahiri-Dutt 2004). I also explored what people think and how they feel about the investments made by the development agent-KPC.

Although these assessments are a good initial step towards promoting understanding, collaboration and partnership between community members and a development agent, they are still located within the 'needs' framework, and do not fully expose the entire livelihood dynamics and the social and economic well-being of women as well as men within communities. This exercise led me to question whether there could be other, better, ways to explore the gendered worlds within mine-affected communities. That exploration led to the development of an action-research project ${ }^{2}$ to integrate gender into the planning, monitoring and evaluation of community development projects devised by KPC.

\section{Asset Mapping}

Asset mapping - as opposed to needs assessment - is not just a technique; it is an alternative way of thinking about community development, in the sense that it is seen as an open-sum perspective that focuses on the abilities and capacities, rather than the deficiencies, of the community. ${ }^{3}$ Whereas conventional community development is often implemented in a 'top down' and 'outside-in' manner, assets-based community development is 'inside-out': the dependence on the outside expert or consultant as a direct implementer of projects is minimal. The emphasis in 'Asset-Based Community-Driven' (ABCD) development processes is on the community's or on an individual's ability to

\footnotetext{
1 Needs assessments are systematic explorations of the way things are for women and the way they should be, and of what people are thinking and how they feel (Barry et al. 2000). Guy (1996) thinks that while information from a needs assessment study is valuable and useful, the process of gathering such information itself is also valuable in itself.

2 See Chapter 1 of this volume for further details of the ANU-KPC, ARC-funded Linkage Project, 'Creating Empowered Communities: Gender and Sustainable Livelihoods in a Coal Mining Region in Indonesia'.

3 Community assets may include the collective talents and skills of community members; existing networks and associations, institutions; physical assets such as land, buildings and equipment; economic assets such as local businesses and exchanges; and cultural assets such as heritage and histories.
} 
play a 'catalytic role' as an awareness-builder as well as a facilitator and learner. The ABCD process is inherently optimistic and one that focuses on strengths rather than the problems and deficits that are identified in needs-based assessments. The problem with this approach is that there is a possibility that the community might internalise some of the deficiency attitudes and come to depend on outside resources or professional experts to find solutions to their problems. Experience tells us that when such a solution is 'found' by others for a community, it generally is not sustainable. Assets-based assessment methods are thus becoming popular for non-government organisations (NGO) and donorsponsored community empowerment programs in Latin America and Africa. ${ }^{4}$

\section{What is New in this Work?}

The challenge in the fieldwork reported here was to combine an assets-based approach with gender-sensitive tools to understand the benefit streams and impacts of development projects run by KPC on men and women in the community. A further challenge was to undertake the research during the project cycle rather than at the end, which is usually when most M\&E tools are used, although monitoring is typically undertaken as an ongoing process.

First, our evaluation occurred not after the project was over but during the project cycle, making it essentially a process evaluation rather than an endevaluation. Second, our intention was to offer new ways of assessing and learning that are more inclusive and more in tune with the views and aspirations of those directly affected by the projects. Finally, and most importantly, a great amount of emphasis was put on differentiating our observations and analysis along gender lines. A pre-condition for achieving people-centred development is the removal of existing disparities between the social, economic and political status of women and men. Our project, therefore, deviated from prior M\&E exercises in three key ways by:

1. conducting a 'process evaluation';

2. using participatory $M \& E ;$ and

3. seeing the M\&E process through a gender lens.

4 For example, Goulet (2008) has outlined how a self-conscious framework for understanding how change takes place within a community might be a better approach to initiating change, citing the example of an Ethiopian rural community that become more self-reliant when this approach was taken by the development agent, Oxfam and a local NGO, the Hundee Grassroots Development Initiative. 


\section{Sustainable Livelihoods Approach}

Our research and fieldwork was undertaken within the overall framework known as the 'sustainable livelihoods' approach. Originally developed by Robert Chambers, of the Institute of Development Studies (IDS) in the UK, to understand the complex experience of vulnerability and access to natural resources, the concepts in this approach have been incorporated into the review and impact assessment of development projects and policies on a multidimensional basis (Ashley and Hussein 2001; Nicole 2001; also see FAO and ILO 2009). According to Whitehead (2002: 575), the framework incorporates a sustained critique of externally imposed definitions of poverty, especially the one dimensional income and consumption line approach. The tools used to conduct sustainable livelihoods assessment are still evolving amid significant debate as to their theoretical, methodological and empirical veracity. The lack of quantification in the approach poses a challenge to conventional development planning and makes it difficult to implement in practice, although the general agreement is that the livelihoods approach is useful for a pro-poor focus and holistic analysis of factors that are locally relevant (Turton 2001; Bond and Mukherjee 2002).

As an example, in agricultural research there has been a noticeable move beyond increasing food production to addressing the larger goal of reducing poverty. Adato and Meinzen-Dick (2002) utilised the livelihoods approach for an expanded understanding of poverty that goes beyond income or consumptionbased headcounts and severity measures, to consider the many other factors that poor people in different contexts define as contributing to their vulnerability, poverty and well-being. The sustainable livelihoods framework thus provides a common conceptual approach that has the ability to shift the focus towards livelihood outcomes, rather than project objectives, and to the full range of impacts rather than just cash incomes and physical outputs within the beneficiary community.

The philosophy behind the use of a gender lens is that the empowerment of poor people and particularly poor women is the key to long-term poverty alleviation through community empowerment. Women in poor communities in rural Kalimantan, where our project is located, often hold far less power and official recognition as economic agents than men, while being largely responsible for household chores. The ANU-KPC Linkage Project sought to change this situation and was based on the assumption that community development projects must help women build their confidence, increase their self-reliance and assist them in making decisions and maintaining control over their resources within the family and the community. 
Women living in the rural areas around KPC's mine operation are and have always been active in supplementing family incomes in a number of ways and play important economic roles not only within the household but also through engaging in trade and commerce. Company staff, however, almost always chose to ignore these productive roles and followed the official Indonesian definition which sees the male as the 'household head'. According to Kabeer (2005) such a conflation of sexual or biological difference with gender or social difference arises from the view that the roles, capacities and aptitudes attributed to men and women within a context are rooted in their biology and hence cannot be changed. In deciding to integrate a gender perspective into KPC's community development policy and programs it was recognised early on that the empowerment of women should not increase their burden of work but increase their part in decision-making affecting their communities. The task was to develop an analytical framework that could translate feminist insights into action and integrate gender perspectives into the community development process. The deeply entrenched and institutionalised nature of gender inequalities within the company's bureaucracy was a challenge that all of us involved in the project also had to overcome.

\section{Monitoring and Evaluation with LAST}

$\mathrm{M} \& \mathrm{E}$, in brief, is a basket of tools to assess whether community development projects have succeeded or failed. M\&E is widely used by governments, donor agencies and organisations implementing development projects to provide accountability, indicate to donors the effectiveness of past expenditure, assure them of quality and pinpoint areas of strength and potential weaknesses. While the term 'monitoring' gives the impression of a continuing function - an ongoing supervision during the life of a project or a program - the process of evaluation is a selective exercise to systematically assess progress towards the achievement of an outcome, and is more costly and less frequent than monitoring (UNDP 2002). Koch (1994: 1148) notes: 'Evaluations are usually engaged with measurement, and their results are used by managers to control and predict aspects of the ... service.' In general, M\&E processes focus on inputs (funds, experts, equipment), outputs (number of people trained), outcomes (increased incomes or creation of jobs), impacts (improved health or longevity) and the objectives and goals of projects. These processes can themselves lead to improved capacity amongst those who undertake them. Figure 7-1 displays some of the objectives of M\&E processes. 


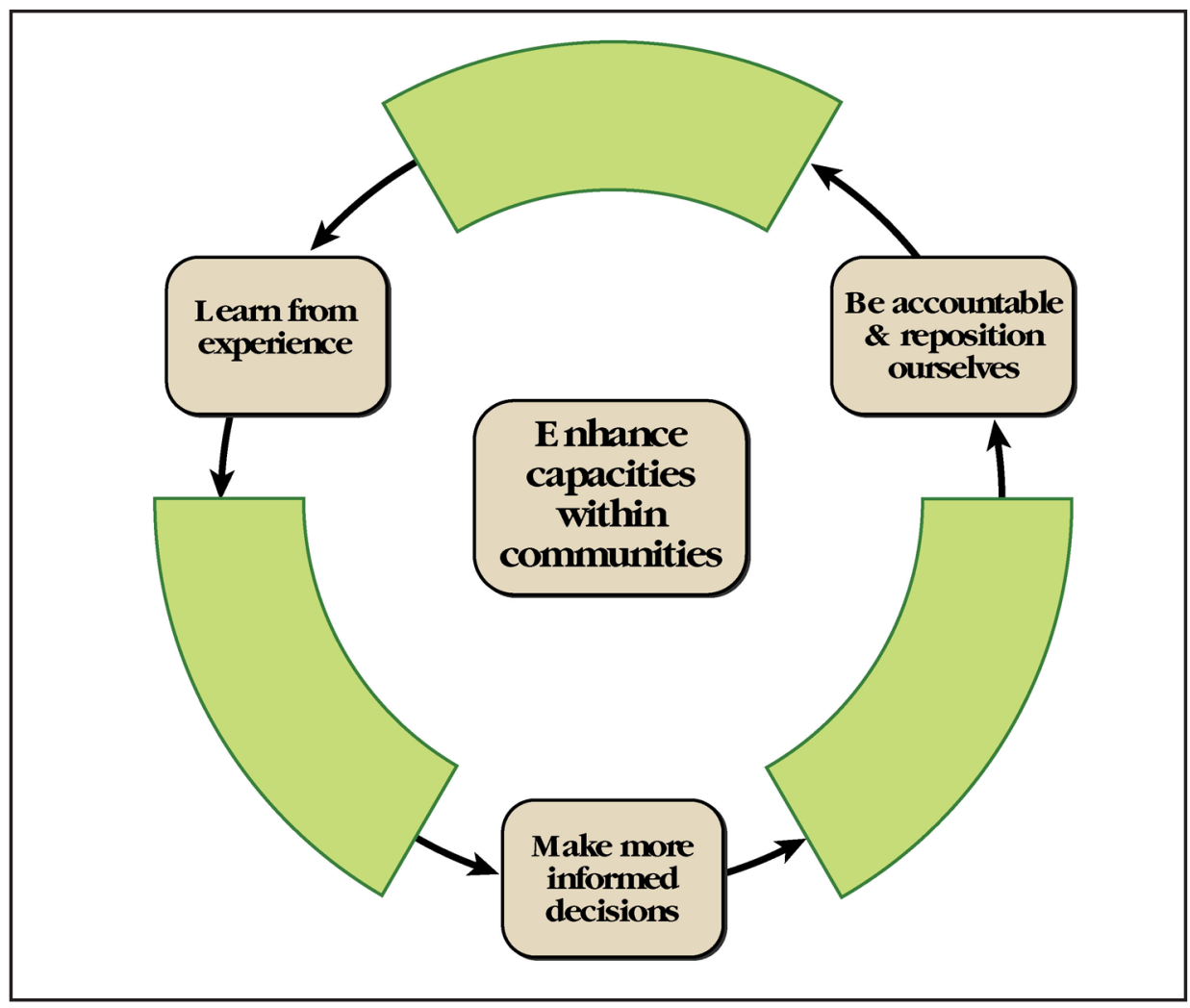

Figure 7-1: Objectives of Monitoring and Evaluation.

Source: Adapted from various sources.

Conventionally, M\&E has been undertaken in the development context by outside experts coming in to measure performance against previously set indicators. For this, a range of procedures and tools have been developed. Often these tools - associated with scientific management of development projects are used uncritically by external experts hired by funding agencies.

Monitoring presents serious challenges for 'process' projects. Instead of just externally assessing (often) sub-optimum impacts, a robust method must internally monitor emerging impacts to enhance the effectiveness of project implementation. For this reason, Bond and Mukherjee (2002) use the term 'impact monitoring' for process evaluation, which is now increasingly demanded by funding agencies and donors. Initially tested in Eastern and Southern Africa as 'stakeholder analysis and local identification of indicators' this method was first used to examine the success and sustainability of farming-based livelihood systems. Such monitoring can detect changes in impact during the implementation of a project. This process was refined by Bond and Mukherjee (2002) into the LAST method, defined by them as: 
A rapid impact monitoring system designed along with primary stakeholders and based on the Sustainable Rural Livelihoods conceptual framework. It is intended to track the ongoing dynamics of five capital assets (usually natural, physical, human, financial and social) essential to household livelihoods as a proxy for impact.

The LAST method was implemented in 2000 by the Indian Farm Forestry Development Co-operative in Pratapgarh, Rajasthan and has been used for retrospective impact assessment by the Gramin Vikas Trust of the Eastern India Rainfed Farming Project in Ranchi, Jharkhand.

\section{The Origins of LAST}

Both conceptually and practically, the LAST method has several predecessors. Conceptually, it derives from the concept of 'sustainable development' but goes beyond an economic definition of development (the production of goods and services for general utility) to incorporate both a social perspective (access, inclusion and intra-generational equity) and an environmental perspective (conservation of natural capital and inter-generational equity). It also incorporates the 'sustainable livelihoods' framework as the analytical basis for the asset endowment of the rural poor. ${ }^{5}$ Essentially it denotes what Robert Chambers (1989) described as a 'new professionalism' within the development field that recognises local autonomy of action and the fostering of innovation within organisations.

Practically, LAST involves methods such as wealth ranking, a Participatory Rural Appraisal (PRA) technique that encourages rural people to classify households in terms of relative wealth or well-being according to their own criteria and judgment. Quality of life indices are used to identify a range of locally meaningful descriptions of household situations from worst to best known, which participants then scale and score. Bond and Hulme used this method as early as 1992 to investigate the operations of partners in rural India. Within the Sustainable Livelihoods framework, the LAST method begins as a participatory assessment of assets to which rural people have access in order to devise their livelihood strategies. According to Bond and Mukherjee (2002: 808) this is also the end point of LAST, 'as those strategies impact not only on their livelihoods in terms of outcomes (a more traditional source of indicators) but also back on the assets themselves.' Thus, the changing asset base, measured for the five types of capital to which a household has access, can be a useful proxy for impact on livelihoods. Two elements are important in this method:

5 I am aware that seeing 'assets' as capital-based is contentious, but in this instance will avoid that specific debate. 
participation and rapidity. If indicators are derived in a participatory way, they will be locally relevant within relatively homogeneous areas (in terms of ethnicity and biodiversity/agriculture). The method needs to be quick and simple enough for rapid enumeration if it is to be used over many households with a reasonable frequency.

Development projects initiated by external agents, such as the mining company KPC in this case, are notorious for their male bias (Elson 1991). The challenge for us was to track the male bias, identify the roots of such bias and show to all participants how women in rural Kalimantan are dealing with the inherent male bias in development projects by using their limited assets innovatively.

\section{LAST Workshops with Men and Women}

For us, the main vehicle for undertaking LAST was a series of participatory workshops conducted with the project team and project beneficiaries of two of KPC's community development projects. The workshops involved small group discussions, brain-storming and clustering of criteria, field-testing and validation. We invited both women and men to participate in these workshops and used a number of cards, slides and posters, flip charts and boards. Initially women were reluctant to participate with men present, but as we began to speak on the assets and strengths of individuals, families and village communities, women expressed more interest in speaking up. Since the workshops were also used as a means of gender sensitisation, we included broad-ranging discussions on who does what in the community (gender roles), how people lived in the past and the present and how much effect the project has had on women's and men's lives within the household (before-after scenarios). As per Bond and Mukherjee (2002: 808), the main objective was to evolve 'word pictures' for constructing verbal descriptions of asset status. Such word pictures depict the 'worst off' and 'better off' households and also intermediate positions. We had two sets of workshops to identify the impacts on the livelihoods of women and men of two community development projects: a Tie and Dye (T\&D) Project and an Orange Cultivation (OC) Project. The first is based in villages around an urban area and the second is located in a rural cluster of planned transmigration villages located a considerable distance from the nearby town, and characterised by poor transportation options. 


\section{Participant Profile}

There were 11 participants in our workshops from the T\&D project and 23 from the OC project. As the T\&D project involves women community members only, disaggregation by sex was possible only for the OC project, with nine women and 14 men in our workshop. The average age of workshop participants was 34 for women and 42 for men in the OC project, and 41 for women in the T\&D project. Being located in Rantau Pulung, which is the more remote of the village clusters, the OC project featured poorer and less literate participants (12 of the 23 participants had a primary school education only), but there was no relationship between literacy levels and incomes. Similarly, there was no correlation between low educational achievement and income among the T\&D project participants. As many as six OC participants, however, reported 'uncertain' incomes and the greatest concentration of participants were in the Rp450 000-500 000 per month income category. In comparison, those in T\&D project, being located in Sangatta town, reported monthly incomes that had a wider spread: three participants earned less than Rp350 000; three others Rp500 000, while two reported incomes of Rpl 000 000, and one over Rp2 500000 per month.

The level of home ownership was considerably greater for participants in the OC workshop, with only one participant reporting as currently living in a house he did not own, whereas just under half of the participants in the T\&D workshop owned their own home. Of the remainder three reported as living with others and three were renting. These participants had lower income levels (less than Rp400 000 per month). However, there was a positive relationship between home ownership amongst T\&D participants and length of stay - it was uncommon for those living in Sangatta for more than six years to rent or stay with others. The patterns were clear: being from a transmigration area, OC participants tended to own a home (given by the government), and the self-motivated migrants living in or around Sangatta initially either rent and/or stay with others while building up a broader income base.

In terms of gender roles and occupations, as many as eight of the women in the OC Workshop self-identified as 'housewife' and only one identified as 'farmer', while 11 of the men self-identified as 'farmer'. Being urban-based, the participants in the T\&D project represented a wider variety of occupationsfive reported as housewives; two as traders; two as working in small business and two in tailoring/sewing. Of the 23 participants in the OC workshop, 14 reported other sources of income. In our workshops we focused on both the main and secondary sources of income in order to explore the full range of economic activities that the households performed. A large number of farming families in the OC project also reared poultry. One family had cattle, another had a store and one other also depended on hunting. As the T\&D project involved 
women only, the participants reported having husbands who were working in a range of occupations, as truck drivers, casual workers or in small business, but only two female participants were engaged in additional income-generating activities - one in catering and one in sewing.

Sangatta itself is a relatively new urban development in East Kalimantan and so most of the workshop participants came from migrant families. The OC project runs in a transmigration area- 19 participants had lived there for around 10 years, two for eight years and one for nine years - revealing a relative uniformity in the length of stay in the area. The participants in the T\&D project reported periods of residence in Sangatta ranging from one year to 25 years. Similarly, the OC project had far less ethnic diversity: as many as 12 participants were Javanese and four were from Flores, the remainder included two each from the Timur and Sunda ethnic communities, and one each from Bima, Ciamis Jabar and Nusa Tenggara. By comparison, the largest ethnic community represented amongst the T\&D participants was Bugis (three), the rest were made of one person each from Banjar, Banjar Manado, Central Sulawesi, Dayak-Chinese, Kutai Kartanegara, Madura and Toraja.

\section{The Tie and Dye Project}

As described, the T\&D project is an urban-based, 'women only' initiative. There are 40 members of a women's group (Lembaga Pemberdayaan Wanita) involved in the project under the leadership of Ibu Ariati. The focus group meetings were held in her house, as were the training sessions. The project statement read:

Women in Sangatta want to be part of an empowering process and social change, which also involves nature and the environment, and want to produce creative art and innovate through local art and crafts.

The project is still in the early stages; it began in May 2006, and at the time we undertook our fieldwork, there had been only two training sessions and one exhibition of the resulting fabric products. The idea behind the project was to continue a local craft tradition using natural resources sourced from the surrounding area. It was envisaged that the project would strengthen local institutions and involve women in them. The raw materials - both the fabric and the threads - are provided by KPC. The company also hired an expert for the project to train the participants to collect, prepare and use natural dyes. The project was dependent on the materials supplied by KPC. Fixing of the natural dyes is done by using chalk and alum. The fixing is generally effective and the colour does not run except during the first wash, although it is not certain how long the dye lasts over the long-term life of the product. 
During our focus group discussions, participants expressed a range of concerns about the long-term viability of the initiative. A critical issue for the project is that of financial sustainability - once the initial materials are used up, the villagers may not have the means to continue the work and practice the newly acquired skills. Pak Faddin, a member of the Community Empowerment Department of KPC, had looked at the problem of prices both for buying materials and selling the products. The initial materials provided by KPC were bought at inflated prices because KPC is always given higher than normal prices. Should the women go on to buy their own fabric, they will probably manage to negotiate lower prices, especially if sourced from local towns such as Balikpapan or Samarinda, or even ordered from Jakarta. However, the participants faced another problem in getting the product to market, as the group did not yet have connections to shops where they might sell their products. Many of the participants thought that eventually having a small boutique shop would be a way to solve this problem. The main concern of the focus group participants was ensuring long-term commercial viability and independence from KPC, and they saw the main obstacle to this as a lack of initial capital to buy the necessary basic materials. Concern was also expressed about the market potential of the products created by the group. However, as noted by Ibu Marita, the process of learning a new skill - in only a few hours a day - that proved to be useful in earning additional incomes was an empowering experience. Ibu Marita has a small shop from which she sells beads and other trinkets and hopes to also sell the $\mathrm{T} \& \mathrm{D}$ products one day.

\section{The Orange Crop Project}

Orange crops have been planted in Rantau Pulung since the 1990s, when the area was settled through transmigration schemes. The local ecology proved to be ideal for orange cultivation and the shady trees helped to prevent soil erosion. Although a few farmers have started to receive benefits, some have faced problems relating to poor quality harvests which have discouraged local business merchants from purchasing them. Based on these observations and a needs assessment, the OC project was devised as a Community Empowerment program in 2004, primarily to assist farmers to improve their skills and provide them with certified seeds, fertilisers and other technical assistance. The project had a tool supply component in addition to the improved seeds supply, as well as consultations by external experts to provide skills development and training in land preparation, planting, cultivation management and pest control. It also included physical verification by a team comprising agricultural experts, KPC Community Empowerment staff, local government representatives and community members themselves, to eliminate the spread of 'orange virus'. The 
project also included capacity-building through in-house training and study in East Java. As part of the project, field facilitators were employed to visit farmers and gather data to map their perceptions.

The OC project had 115 beneficiaries - less than the number originally envisaged - due to a limited number of seeds being available. All participants were men because in Kalimantan, the ownership of land is usually vested in a man, although women work in family farms. The recruitment of project participants was done more or less informally in meetings with village communities, based on willingness and level of interest and the ability to provide land and other raw materials required to participate. The productivity of orange cultivation in East Kalimantan is higher than the national average. Marketing of the fruit is the responsibility of farmers themselves and Sangatta is the main market, with a high demand for the fruit. Orange is a farm product with cash potential-a household can expect to earn around Rp4.5 million within three years of planting. Oranges also have the potential to diversify the diets of local people, particularly the poor, and provide improved nutrition and health outcomes.

Our initial observation was that the OC project has been gender-blind in the early conception and recruitment stages. Women were not seen as direct beneficiaries and the project primarily targeted men, who owned the family lands. However, although the main beneficiary was in most cases the male head of household, it was quickly discovered that women were frequently involved in the maintenance of orange plantations, as well as the harvesting of the fruit, and sales. During the workshops, it was revealed that women provide a significant amount of labour both in household gardens and orange cultivation. The extension workers also reported that women were hungry for knowledge and many accompanied the visiting agricultural experts when they toured around the village plots during their inspection trips. Women were most likely to be present in the training sessions which covered fertilisation and other elements of plant care. Once the project commenced, the high interest and involvement of women provided impetus for integrating a gender perspective in the OC project. This lead to a number of changes to the project, such as setting the timing of field visits by external experts and extension workers to suit women, and the replacement of expensive chemical fertilisers in favour of organic manure composted from animal dung and household wastes. Women participants argued that although the use of organic nutrients involved more labour, requiring the assistance of their husbands and/or older family members, they reduced costs drastically, as well as their dependence on the company's supply of fertiliser. The use of organic manure, they commented, also decreases exposure to synthetic chemicals and has beneficial effects on health, in particular the skin on the hands.

One of the main difficulties for the project related to culturally-based assumptions about the make-up of rural agricultural communities around Sangatta. While 
the settled Javanese transmigrant communities - most of whom were farmers in Java - adapted easily to a farming-based livelihood and thus received the most benefits from the project, local Dayak and Kutai peoples who have traditionally had a forest-based livelihood failed to take full advantage of the project. In envisioning the participants as land-based farmers, the project left out such groups of people-an exclusion which indirectly encouraged them to take up slash and burn agriculture.

In terms of practical obstacles, getting the fruit to market proved difficult, as the villages were located on average about two to three hours from Sangatta. This resulted in the formation of a buyers' market, which the trader from Sangatta visited once or twice a week to collect the oranges, leading to the families receiving a lower price than they could get in town. For women, poor access to the market and the lack of transportation facilities were the two biggest hurdles which prevented them from taking full advantage of the program.

In conversations with some of the participants of the OC project, it emerged that many felt that the project had positively contributed to the well-being of farming families. Improvements in the quality of life had not only come about from access to greater incomes, but as one participant observed, a 'sense of selfreliance' and self-sufficiency had been crucial in making the project a welcome intervention. At the same time, there was an awareness of the need to involve non-Javanese communities in the OC project. The feeling that the project had involved women without fully acknowledging their contributions officially as beneficiaries or participants was also strong.

\section{Analysing Gender with Participants}

Women living in villages in and around the mine operation play a number of roles at home, in the communities and as productive agents. At home, they are mothers and housekeepers, cooks and carers, but they also act as producers of a significant amount of food and other crops, tend to fruit trees and livestock. Most women make trade-offs in allocating their time, labour and productive resources between their varied roles and obligations. Most household plots display these mixed responsibilities and combine production cycles where the primary responsibility for the crops can be shared. Almost the entire range of farming activities involves a collaborative effort between women and men. Women are responsible for domestic livestock, vegetables and tree crops around their households. Digging and land preparation are seen primarily as men's tasks, but caring for the soil, weeding and regular watering are women's chores. The economic status of the family has a distinct influence on a woman's involvement in the family farm. Many Javanese women living in Rantau Pulung 
are conscious of their position in the social hierarchy. Women from more affluent families or women with better educations spend less time in the field and more time cooking and in other tasks within the household. Going out and working in the field is also associated with a darkening of the complexion due to the exposure to the sun and other elements. Social and gender norms tend to be followed more strictly by women who have alternative means that allow them to stay away from the sun.

Some homes in both Rantau Pulung and Sangatta double as small grocery stores or shops supplying provisions to local families. Both the husband and wife may participate in running these small enterprises and gender roles are not always strictly compartmentalised, but may overlap significantly. However, one T\&D participant, Ibu S, who sells food at the market to support her family, receives no support from her husband. She was reluctant to comment on the project and was unable to say whether she thought she might possibly make more money through the project. She was generally shy and quiet, with no education, but agreed that she has made some new friends through the program, which has expanded her social network. However, it is important to remember that because Sangatta is urbanised and hosts many migrant families, the boundaries of the households there tend to be less permeable and changeable than those families living in Rantau Pulung.

Since the rural household is the primary site of both production and consumption, we used households as starting points in our focus group discussions. Initial discussion focused on the 'activity locus' - identifying where activities are performed by a family - in the family field, shop or in the outside community. This revealed the extent of women's mobility as compared to men. For community development projects, gender-differentiated mobility has implications for project delivery and reaching the most disadvantaged. Although most projects are assumed to be gender-neutral, they are not targeted to homogeneous populations within a community. As noted by Overholt et al. (1985), the gender-based division of labour, as well as access to and control over resources and benefits are likely to differ within a community. Hence we aimed to develop separate activity profiles for women and men at each of the project sites.

For the United Nations (UN) funded project, Household, Gender and Age, researchers Masini and Stratigos (1991) from the UN University found that many men and women used the 'life-course approach' as the most suitable for capturing the impacts of macro-changes on women and households. They found that talking about changes with individuals within the household was useful even for women with very little education. In our focus groups, we used a version of this method: instead of individual interviews we listened to individual men's and woman's free-flowing narrations. As women recalled their family trajectories they recalled what had happened to them in the course of 
their lives and began to reconstruct their life histories, and even related major changes in terms of events in the wider environment. The life-course method also revealed the roles, activities and the status of the individual woman or man in relation to the changes that development projects introduced into their lives. Such free-flowing description produces what is described in gender analysis as an 'activity profile' that gives a more or less accurate assessment of the interaction between women and external projects (Overholt et al. 1985). As the UN researchers noted, an important task in the process is 'how one categorises activities conceptually', and that was our main thrust in tracking gendered access to assets.

Three major questions were raised in our gender analysis:

1. Who does what, when and where in the household or home-based enterprise, on or off the farm, and in terms of household maintenance?

2. Who has ownership, control over or access to resources, production, knowledge, technology, time and decision-making power?

3. Who benefits from the existing organization of production, community and household resources?

Discussion of these questions during the focus groups often brought us back to the issue of gender-based roles and responsibilities, and differential control over resources. For example, although women earned independent incomes and managed household farms, they noted that this did not necessarily enhance their value to their husbands. Often, the project targeted men as farmers and receivers of training, leading to an erosion of self-esteem and confidence. For example, one OC participant, Ibu K, felt that the project added to her knowledge and increased her skills, but did not directly address her needs or see her as a recipient of the project's benefits. Ibu K had a baby and when she came to the training sessions or visits by experts, she needed to bring him along. Sometimes she received comments that she should not have brought the baby to public meetings. Although she hardly spoke during the group discussions, she was forthcoming with her views during one-to-one sessions, and described how, in spite of being at the margins of the development project, her life was influenced by it.

\section{Main Agents and Factors of Change}

Change at both the individual and the family level was discussed with the participants in the OC workshop. Both male and female participants reported that at the family level, success depends on an effective interaction between the major agents: the farmer; the local government and the Company (KPC). 
The diagram we developed, however, pictured the government as a stand-alone entity. This has a historical reference: KPC was able to establish a 'patronclient' relationship with the communities around its operation sites before the Indonesian government arrived at its doorstep through the decentralisation of administration. Figure 7-2 illustrates the continued heavy dependence of the community on KPC's community development programs.

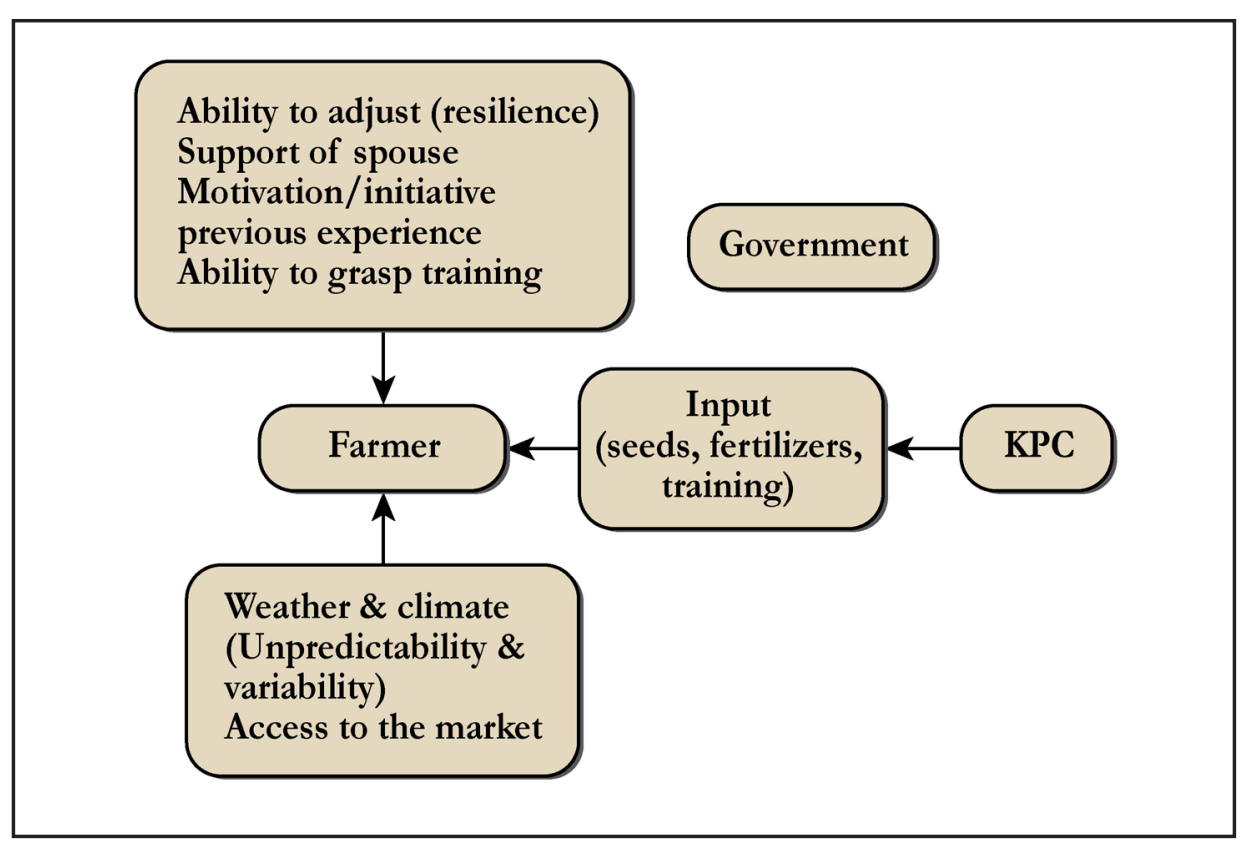

Figure 7-2: Agents and factors of change.

Source: Adapted from various sources.

In the past, innovations in farming techniques grew out of conversations with village elders, who offered suggestions based on their knowledge of traditional farming techniques. With intensive logging, there are now fewer trees available and the water-retentive capacity of the badly eroded soil has declined considerably. As the area has grown drier, the village elders recommended terracing the fields and raising embankments to prevent runoff. At the individual level, participants placed importance on psychological factors like initiative or motivation, and prior exposure, experience or education to take advantage of training. A number of male participants emphasised the support of their spouse as critical for success. Interestingly, many women felt that a 'general support network' - such as the availability of neighbours or relatives for child carewas an important factor besides prior training and knowledge or exposure. 


\section{Success Factors in Asset-Building}

To follow up, we discussed factors for success. The participatory exercises generated a significant amount of discussion between women and men. These exercises drew heavily on the creativity of individual participants, with us using stories and examples to break the silence on issues relating to women's and men's work burdens. 'What are the factors for success?' was a theme that was debated extensively, and there were significant differences between women and men in accounting for success. Saifuddin, one of the more successful farmers, observed wisely: 'Success is relative, the most important thing is that I have learnt something new. The land that was lying fallow around their houses has now been put to use for the families, and earning extra incomes'. For many other men like him, success meant being able to 'put to use' land that was 'lying fallow'. Women, on the other hand put more importance on 'learning something new', and pointed out that learning a new skill gives them the opportunity to use it to add to the family's income. Ibu H, for example, is a middle-aged single woman whose husband died at an early age, leaving her with the responsibility of bringing up three children. She took up a tailoring course and sought money from a local moneylender to start her own tailoring business. Now she makes employee uniforms and embroiders the company logos for KPC as well as its local contractors.

\section{Word Pictures: 'Before-After' Asset Differences}

At the next stage, we developed word pictures based on the worldviews of the participants. The outcomes were practical and realistic and helped us to take up a rapid appraisal to compare the statements with reality, allowing the community to own the method. The 'worst picture' of a household's livelihood status was envisaged as little or no land, a limited amount of food available from the farm, poor-quality land, droughts destroying the orange plants, slash and burn causing forest fire, the presence of illegal logging and having no livestock. The 'best picture' of a household was envisaged as more land, more produce from land, good orange crops, greater access to markets, own transport and good rainfall. Following the discussions in the workshops, the participants themselves drew a 'before' and 'after' picture in terms of their own livelihood status (see Table 7-1). 
Table 7-1: Before-after word pictures.

\begin{tabular}{|c|c|c|}
\hline Before-After (Impact) & Before & After \\
\hline Best off & - & Saifuddin, Tris \\
\hline Better off & Tris & $\begin{array}{c}\text { Basuki, Bai, Wahidin, Imam, } \\
\text { Yohanis, Sugiran }\end{array}$ \\
\hline Medium (no change) & - & $\begin{array}{l}\text { Remi, Said, Mukhroji, } \\
\text { Vincent }\end{array}$ \\
\hline Worse off & - & - \\
\hline Worst off & $\begin{array}{l}\text { Basuki, Dul, Mukhroji, Vincent, } \\
\text { Yohanis, Sugiran }\end{array}$ & Dul \\
\hline
\end{tabular}

Source: Author's own data.

At this stage in the LAST method, we prepared an assessment sheet to compare it with the reality of a particular household. This involved a rapid assessment process to find which description or collection of indicators fitted closest to the reality of the individual woman and man within a household. For this process, individual questions were not asked for every indicator; rather we used our judgment on the relevant part and combined direct observation with semistructured questioning. In the field, this took approximately 30 minutes or so for a single household for the LAST enumeration. The LAST sheet was then used as a checklist and for recording the closest situation to the household and did not intrude on the interview.

\section{Changing Self}

Overall, the women in villages who had participated in company-sponsored projects felt that they flourished as individuals; one noting she was 'like a changed person'. One participant, Ibu S, observed that before she started the business, she could not imagine that it was possible for her to undertake such a venture. But now she thinks: 'If I could do this business - rather than staying at home - I could earn more.' The comments echoed the sentiments of feeling 'richer because of more knowledge' and feeling 'increased enthusiasm'. This was true in particular of participants in the OC group from which one person had been sent for intensive training in Bandung. One woman made the observation that, 'now that I have learnt something, I want to do it better.' A number of women expressed a greater understanding and appreciation of self-reliance through the interviews. One said, 'So far KPC has provided the materials but I want to buy them myself.' Another said, 'I want to work continuously to make sure that my children are better off.'

More so than men, women participants criticised the short life spans of individual development projects, which tend to be funded in small bursts as 
funds are made available on a project-life basis by the company. Another point made often by women was the need for more capital to be made available directly to the individual ('will I get credit to run the business?'). These needs reflect Indonesian social institutions that make women's contributions invisiblewomen did not own land, lacked education and were neglected in training programs, and hence did not receive credit.

The manner in which women have dealt with these systemic shortcomings is innovative and clearly reveals the value of an asset-based approach. Traditional 'women's groupings' such as Qur'an study groups or book-reading groups provide women with the necessary tools to deal with market-based processes that attempt to leave them by the wayside. A significant role is played in rural communities by a traditional grouping of households into desa wisma, or families of ten. They act as vital support networks in swiftly changing rural contexts like the one we were working in-experiencing rapid urbanisation; an influx of immigrants and changing cultural and natural landscapes (changes that are very common in remote areas that experience rapid changes because of mining-led development). Women in these groups of ten families help each other in various ways - not only by lending crucial capital resources during a wedding or medical emergency, and to set up businesses, but also by helping each other by looking after each other's children and caring for each other's families.

Important lessons were learnt in the course of the research by all participants. True to the essence of action-research, our research certainly had significant impacts on those who took an active and engaged part in it. Not only did the male bias in the company's development projects become apparent to all concerned, a number of community extension personnel acknowledged the new and gendered way in which they began to see what, to them, was previously a homogeneous and externalised 'community'. This bias was neither explicit nor intentional, but it operated nevertheless in favour of men as a gender, and against women as a gender. A number of men contributed substantially to the research process and once identified, were interested in combating the bias. The process of research was also transformative for us, participants from outside. It allowed us to understand the important roles played by women and the contributions they made in building the household and making the community. It also showed that alternative ways of seeing the world are possible; that poor and rural women have a number of valuable support systems that need more nuanced understanding and enhancement. This is a vital step in making development projects beneficial to both women and men. Once recognised, the asymmetries in the lived experiences of women and men, seen in the course of 
Gendering the Field

research through the LAST method, can be addressed and combated in time. Further, the complementarities in women and men's roles be made equitable and just, and the strengths that women depend on can be supported.

\section{References}

Adato, M. and R. Meinzen-Dick, 2002. 'Assessing the Impact of Agricultural Research on Poverty using Sustainable Livelihoods Framework.' Sussex: IDEAS.

Ashley, C. and K. Hussein, 2000. 'Developing Methodologies for Livelihood Impact Assessment: Experience of the African Wildlife Foundation in East Africa.' London: Overseas Development Institute (Working Paper 129). Viewed 17 July 2010 at http://www.odi.org.uk/resources/download/2032. pdf

Barry, M.M. A. Doherty, A. Hope, J. Sixsmith and C. Cecily Kelleher, (2000). 'A community needs assessment for rural mental health promotion.' Health Education Research 15(3): 293-304.

Bond, R. and N. Mukherjee, 2002. 'Livelihood Asset Status Tracking: An Impact Monitoring Tool?' Journal of International Development 14: 805-15.

Chambers, R., 1989. 'Vulnerability: How Do Poor People Cope?' IDS Bulletin 20(2): $1-8$.

Elson, D. (ed.), 1991. Male Bias in the Development Process. Manchester and New York: Manchester University Press.

FAO (Food and Agriculture Organisation) and ILO (International Labour Organisation), 2009. The Livelihood Assessment Toolkit: Analysing and Responding to the Impact of Disasters on the Livelihoods of People, Rome and Geneva. Rome and Geneva: FAO and ILO.

Goulet, L., 2008. 'The Road to Self-Reliance-ABCD, Case Study.' In D. Green (ed.), From Poverty to Power: How Active Citizens and Effective States Can Change the World. London: Oxfam International.

Guy, S.M., (1996). Community needs assessment survey guide. Utah: Utah State University Extension.

Kabeer, N. 2002. 'From Feminist Insights to an Analytical Framework: An Institutional Perspective on Gender Inequality.' In N. Kabeer and R. Subrahmanian (eds), Institutions, Relations and Outcomes: A Framework and Case Studies for Gender-Aware Planning. New Delhi: Kali for Women. 
Koch, T., 1994. 'Beyond Measurement: Fourth Generation Evaluation in Nursing.' Journal of Advanced Nursing 20: 1148-155.

Lahiri-Dutt, K., 2004. 'Gender Needs Assessment Report.' Canberra: ANU. Viewed 20 January 2011 at http://empoweringcommunities.anu.edu.au/ documents/LahiriDutt_2004_GenderNeedsAssessment.pdf

Massini, E. and S. Stratigos (eds), 1991. Women, Households and Change. Tokyo: United Nations University Press.

Nicole, A., 2001. 'Adopting a Sustainable Livelihoods Approach to Water Projects: Implications for Policy and Practice.' Overseas Development Institute, London (ODI Working Paper 133).

Overholt, C., M.B. Anderson, K. Cloud and J.E. Austin (eds), 1985. Gender Roles in Development Projects: A Case Book. West Hartford: Kumarian Press.

Turton, C., 2001. Livelihood Monitoring and Evaluation: Improving the Impact and Relevance of Development Interventions. Sussex: Institute of Development Studies.

UNDP (United Nations Development Programme), 2002. Handbook on Monitoring and Evaluation for Results. New York: UNDP Evaluation Office.

Whitehead, A., 2002. 'Tracking Livelihood Change: Theoretical, Methodological and Empirical Perspectives from North-west Ghana.' Journal of Southern African Studies 28(3): 575-98. 